\title{
Fluorescence Characteristics of Methoxycoumarins as Novel Fluorophores
}

\author{
Akira Takadate*, Toshinobu Masuda*, Chiyomi Murata*, Toshiharu Tanaka*, \\ Mitsuru IRIKURA** and Shujiro GoYA** \\ * Daiichi College of Pharmaceutical Sciences, Minami, Fukuoka 815, Japan \\ **Faculty of Pharmaceutical Sciences, Kumamoto University, Kumamoto 862, Japan
}

\begin{abstract}
The fluorescence characteristics of various methoxycoumarin fluorophores for the development of fluorescence reagents were examined in relation to their structures. The fluorescence emission mechanisms were also considered from the viewpoint of the intramolecular charge-transfer (CT) between methoxyl substituents and the coumarin ring. The arrangement of 6-methoxyl and 3-acetyl group pairs on the coumarin ring significantly contributed to the fluorescence enhancement through the intramolecular CT. We found that the structural features of methoxycoumarins required for intense fluorescence are to hold both diether bonds at the 6- and 7-positions and an electron-withdrawing group at the 3position, as shown in 3-acetyl-6,7-dimethoxycoumarin with 0.52 in quantum yield.
\end{abstract}

Keywords Methoxycoumarin, fluorophore, fluorescence reagent, fluorescence emission mechanism, intramolecular charge-transfer

A number of fluorogenic compounds have been widely used as reagents for microanalysis because they are both highly sensitive and selective. In general, most of the analytical reagents so far developed have been prepared by introducing some reactive groups coupled with functional groups in analytical samples into appropriate fluorophores. The reagent design, based upon detailed information concerning primary fluorophores, including their emission mechanisms, should permit a more efficient development of a variety of analytical reagents. However, only a few studies on the characteristics of the fluorophores under consideration for reagent design have been performed. ${ }^{1,2}$ Of many fluorophores, coumarins having variable fluorescence properties arising from the ring structure differs from those of rigid aromatic rings, such as anthracene or pyrene, have led to much interest not only concerning their application to analytical reagents, but also to an understanding of their emission mechanisms. We have reported on various coumarins as fluorescence derivatization reagents for high-performance liquid chromatographic analysis ${ }^{3-7}$, fluorescence probes for drug-protein binding studies ${ }^{8}$ and fluorescence ionophores. ${ }^{9}$ This paper describes the fluorescence characteristics of a series of methoxycoumarin fluorophores in relation to their structural features for reagent design.

\section{Experimental}

All chemicals were of reagent grade, unless noted otherwise. The solvents (Luminasol) used for the fluorescence and absorption spectral measurements were purchased from Dojindo Laboratories (Kumamoto, Japan). Coumarins (I, II, and VII) ${ }^{10}$ and acetylcoumarins (III - VI, VIII and IX) ${ }^{11}$ were synthesized by means of the Pechmann ${ }^{12}$ and Knovenagel ${ }^{13}$ type reactions from the corresponding phenols or hydroxybenzaldehydes ${ }^{14}$, respectively. The structures of the products were confirmed based on the known melting point, proton nuclear magnetic resonance $\left({ }^{1} \mathrm{H}-\mathrm{NMR}\right)$ and mass spectral data.

The physical and spectral data of $\mathbf{V}, \mathbf{V I}$ and IX were as follows:

[V] mp $243-244^{\circ} \mathrm{C},{ }^{1} \mathrm{H}-\mathrm{NMR}\left(\mathrm{CDCl}_{3}\right) \delta: 2.34(3 \mathrm{H}, \mathrm{s}$, $\left.\mathrm{C}_{7}-\mathrm{CH}_{3}\right), 2.73\left(3 \mathrm{H}, \mathrm{s}, \mathrm{C}_{3}-\mathrm{COCH}_{3}\right), 3.89\left(3 \mathrm{H}, \mathrm{s}, \mathrm{C}_{6}-\right.$ $\left.\mathrm{OCH}_{3}\right), 6.91\left(1 \mathrm{H}, \mathrm{s}, \mathrm{C}_{8}-\mathrm{H}\right), 7.12\left(1 \mathrm{H}, \mathrm{s}, \mathrm{C}_{5}-\mathrm{H}\right), 8.49(1 \mathrm{H}$, $\left.\mathrm{s}, \mathrm{C}_{4}-\mathrm{H}\right)$. MS $m / z: 232\left(\mathrm{M}^{+}\right)$.

[VI] mp $199-200^{\circ} \mathrm{C},{ }^{1} \mathrm{H}-\mathrm{NMR}\left(\mathrm{CDCl}_{3}\right) \delta: 2.22(3 \mathrm{H}, \mathrm{s}$, $\left.\mathrm{C}_{6}-\mathrm{CH}_{3}\right), 2.71\left(3 \mathrm{H}, \mathrm{s}, \mathrm{C}_{3}-\mathrm{COCH}_{3}\right), 3.94\left(3 \mathrm{H}, \mathrm{s}, \mathrm{C}_{7-}\right.$ $\left.\mathrm{OCH}_{3}\right), 6.78\left(1 \mathrm{H}, \mathrm{s}, \mathrm{C}_{8}-\mathrm{H}\right), 7.36\left(1 \mathrm{H}, \mathrm{s}, \mathrm{C}_{5}-\mathrm{H}\right), 8.48(1 \mathrm{H}$, $\left.\mathrm{s}, \mathrm{C}_{4}-\mathrm{H}\right)$. MS $m / z: 232\left(\mathrm{M}^{+}\right)$.

[IX] mp $162-163^{\circ} \mathrm{C},{ }^{1} \mathrm{H}-\mathrm{NMR}\left(\mathrm{CDCl}_{3}\right) \delta: 2.33(3 \mathrm{H}, \mathrm{s}$, $\left.\mathrm{C}_{6}-\mathrm{CH}_{3}\right), 2.39\left(3 \mathrm{H}, \mathrm{s}, \mathrm{C}_{7}-\mathrm{CH}_{3}\right), 2.72\left(3 \mathrm{H}, \mathrm{s}, \mathrm{C}_{3}-\mathrm{COCH}_{3}\right)$, $7.16\left(1 \mathrm{H}, \mathrm{s}, \mathrm{C}_{8}-\mathrm{H}\right), 7.37\left(1 \mathrm{H}, \mathrm{s}, \mathrm{C}_{5}-\mathrm{H}\right)$, and $8.46\left(1 \mathrm{H}, \mathrm{s}, \mathrm{C}_{4}-\right.$ H). MS $m / z: 216\left(\mathrm{M}^{+}\right)$.

\section{Apparatus}

The melting points were measured with a Yanagimoto micro-melting point apparatus, and were uncorrected. The absorption and fluorescence spectra were taken with a Hitachi U-3210 spectrophotometer and a Hitachi F- 
4000 fluorescence spectrophotometer, respectively. The fluorescence quantum yields were determined according to the method of Paker and Rees ${ }^{15}$, the value (0.55) for quinine sulfate in $0.5 \mathrm{M} \mathrm{H}_{2} \mathrm{SO}_{4}$ was used as the standard. The time-resolved fluorescence spectra were taken with a Horiba NAES-700F spectrofluorometer. A nanosecond-flash lamp filled with hydrogen was used as an excitation light source. A sequence of light-pulses from this lamp was passed through a Hoya $U \mathbf{3 6 0}$ glass filter and a solution filter $\left(\mathrm{CuSO}_{4} \cdot 5 \mathrm{H}_{2} \mathrm{O}, 250 \mathrm{~g} / \mathrm{l}\right)$, then focused upon a rectangular sample cell made of quartz. The fluorescence lifetime measurements were based on an analysis of the fluorescence decay curves. ${ }^{1} \mathrm{H}-\mathrm{NMR}$ were obtained with a JEOL JNM-GSX 500FT-NMR spectrometer using tetramethylsilane as an internal standard. The following abbreviations are used: $s$, singlet; d, doublet; t, triplet; $\mathrm{m}$, multiplet. The mass spectra (MS) were taken with a JEOL JMS-DX303 spectrometer.

\section{Results and Discussion}

Although coumarin by itself is non-fluorescent, its derivatives with electron-donating groups at the 7position develop intense fluorescence. This fluorescence emission mechanism has been interpreted based on the intramolecular charge-transfer (CT) arising from a push-pull electron relay, namely, electron-transfer from a substituent (donor) at the 7-position to a lactone carbonyl group (acceptor) on the coumarin ring. ${ }^{1}$ Also, the substituent effects in 7-substituted coumarins were explained based on the Hammett rule by approximating them to the disubstituted benezene (DSB)-model. According to this model, the relationship between substituents at the 7-position and the lactone carbonyl group corresponds to that of para-disubstituted benzenes for an electronic effect. Therefore, the substituents at the 6-position corresponding to the meta-relation of the lactone carbonyl group can be realized under these conditions.

The absoption and fluorescence spectral data of methoxycoumarins (I - VIII) prepared here are summarized in Table 1. The absorption maxima ( $\left.\lambda_{\mathrm{UV}} \mathrm{s}\right)$ and the fluorescence emission maxima $\left(\lambda_{F} s\right)$ of I-VIII shifted, on the whole, to a longer wavelength accompanying an enhancement of the absorbance and fluorescence intensities with increasing the solvent polarity. Their fluorescence quantum yields increased much more in methanol than in other solvents. This spectral behavior of I and III - VIII is essentially similar to that of II, as pointed out by Hinohara et al. ${ }^{1}$ The lower quantum yields in acetonitrile than in methanol seem to be due to a difference in the solvation of the fluorophores with both solvents in the excited state. This may permit the fluorescence characteristics of these coumarins to be understood based on the viewpoint of their DSB-model treatment and intramolecular CT. Further characterization, including the emission mechanism, was performed based on the data obtained in methanol, because of the high quantum yield.

\section{Monomethoxycoumarins}

The $\lambda_{\mathrm{UV}} \mathrm{s}$ and $\lambda_{\mathrm{F}} \mathrm{S}$ of monomethoxycoumarins in

Table 1 Absorption and fluorescence spectral data of methoxycoumarins in various solvents

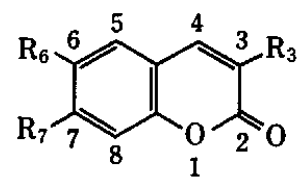

\begin{tabular}{|c|c|c|c|c|c|c|c|c|}
\hline $\begin{array}{c}\text { Compound } \\
\text { No. }\end{array}$ & $\mathbf{R}_{3}$ & $\mathbf{R}_{6}$ & $\mathbf{R}_{7}$ & & Acetonitrile & Methanol & Dichloromethane & Benzene \\
\hline \multirow[t]{2}{*}{ I } & $\mathbf{H}$ & $\mathrm{OCH}_{3}$ & H & $\mathrm{UV} \lambda_{\max } / \mathrm{nm}$ & 344 & 347 & 346 & 349 \\
\hline & & & & $\mathrm{F} \lambda_{\max } / \mathrm{nm}$ & $441(0.01>)$ & $453(0.02)$ & $438(0.01>)$ & $437(0.01>)$ \\
\hline \multirow[t]{2}{*}{ II } & $\mathbf{H}$ & $\mathrm{H}$ & $\mathrm{OCH}_{3}$ & $\mathrm{UV} \lambda_{\max } / \mathrm{nm}$ & 323 & 323 & 326 & 327 \\
\hline & & & & $\mathrm{F} \lambda_{\max } / \mathrm{nm}$ & $391(0.01>)$ & $390(0.05)$ & $388(0.01)$ & $389(0.01>)$ \\
\hline \multirow[t]{2}{*}{ III } & $\mathrm{COCH}_{3}$ & $\mathrm{OCH}_{3}$ & $\mathbf{H}$ & $\mathrm{UV} \lambda_{\max } / \mathrm{nm}$ & 375 & 375 & 378 & 381 \\
\hline & & & & $\mathrm{F} \lambda_{\max } / \mathrm{nm}$ & $491(0.02)$ & $506(0.06)$ & $485(0.01)$ & $480(0.01>)$ \\
\hline \multirow[t]{2}{*}{ IV } & $\mathrm{COCH}_{3}$ & $\mathbf{H}$ & $\mathrm{OCH}_{3}$ & $\mathrm{UV} \lambda_{\max } / \mathrm{nm}$ & 355 & 358 & 360 & 360 \\
\hline & & & & $\mathrm{F} \lambda_{\max } / \mathrm{nm}$ & $399(0.01>)$ & $428(0.01>)$ & $423(0.01>)$ & $433(0.01>)$ \\
\hline \multirow[t]{2}{*}{$\mathbf{V}$} & $\mathrm{COCH}_{3}$ & $\mathrm{OCH}_{3}$ & $\mathrm{CH}_{3}$ & $\mathrm{UV} \lambda_{\max } / \mathrm{nm}$ & 376 & 378 & 382 & 381 \\
\hline & & & & $\mathrm{F} \lambda_{\max } / \mathrm{nm}$ & $483(0.12)$ & $501(0.25)$ & $476(0.09)$ & $467(0.02)$ \\
\hline \multirow[t]{2}{*}{ VI } & $\mathrm{COCH}_{3}$ & $\mathrm{CH}_{3}$ & $\mathrm{OCH}_{3}$ & $\mathrm{UV} \lambda_{\max } / \mathrm{nm}$ & 368 & 369 & 372 & 370 \\
\hline & & & & $\mathrm{F} \lambda_{\max } / \mathrm{nm}$ & $428(0.01>)$ & $436(0.01)$ & $429(0.01>)$ & n.d. ${ }^{a}$ \\
\hline \multirow[t]{2}{*}{ VII } & $\mathbf{H}$ & $\mathrm{OCH}_{3}$ & $\mathrm{OCH}_{3}$ & $\mathrm{UV} \lambda_{\max } / \mathrm{nm}$ & 342 & 344 & 346 & 347 \\
\hline & & & & $\mathrm{F} \lambda_{\max } / \mathrm{nm}$ & $430(0.07)$ & $432(0.25)$ & $423(0.09)$ & $421(0.02)$ \\
\hline \multirow[t]{2}{*}{ VIII } & $\mathrm{COCH}_{3}$ & $\mathrm{OCH}_{3}$ & $\mathrm{OCH}_{3}$ & $\mathrm{UV} \lambda_{\max } / \mathrm{nm}$ & 383 & 385 & 382 & 389 \\
\hline & & & & $\mathrm{F} \lambda_{\max } / \mathrm{nm}$ & $466(0.29)$ & $482(0.52)$ & $406(0.18)$ & $456(0.05)$ \\
\hline \multirow[t]{2}{*}{ IX } & $\mathrm{COCH}_{3}$ & $\mathrm{CH}_{3}$ & $\mathrm{CH}_{3}$ & $\mathrm{UV} \lambda_{\max } / \mathrm{nm}$ & 350 & 351 & 359 & 359 \\
\hline & & & & $\mathrm{F} \lambda_{\max } / \mathrm{nm}$ & n.d. ${ }^{a}$ & n.d. ${ }^{a}$ & n.d. ${ }^{a}$ & n.d. ${ }^{a}$ \\
\hline
\end{tabular}

a. Not detected. Parentheses stands for the quantum yield. 
methanol were at 347 and $453 \mathrm{~nm}$ for I and 323 and $390 \mathrm{~nm}$ for II. Although the 6-methoxyl group in I corresponded to the meta-position of the lactone carbonyl group according to the DSB-model, its maximal wavelengths were longer than those of II, in which the 7methoxyl group corresponds to the para-position. Although the reasons for these results are not fully understood, an electronic effect via the lactone ring oxygen atom from the 6-methoxyl group is probable in the coumarin ring. Yoshida et al. ${ }^{16}$, have described in a rule concerning the relationship between the chemical structures and fluorescence properties that coumarin fluoresces when electron-donating groups are introduced into electron-defficient positions (4-, 5- and 7-positions) and when electron-withdrawing groups are introduced into electron-sufficient positions (3-, 6- and 8-positions). Actually, 6- and 8-hydroxycoumarins are non-fluorescent. ${ }^{16}$ On the other hand, I, methylether of 6hydroxycoumarin, apparently fluoresced with a quantum yield of 0.02 , though it was smaller than that of II, corresponding to the para-relation in the DSB-model. This is considered to be based upon the difference in the solvation effects between the hydroxyl and methoxyl groups in the excited state.

\section{Effects of an acetyl group}

Compounds III and IV, which have an acetyl group at the 3-position, have another electron-withdrawing group in addition to that of the lactone carbonyl. Although it is slightly difficult to designate the electron-transfer route between the methoxyl and acetyl groups in these coumarins, the 6-methoxyl group in III from the electronic effect of the 3-acetyl group within the lactone ring may be considered to correspond to the para-relation of the acetyl group, while the 7-methoxyl group in IV corresponds to the meta-relation. Therefore, an another electron-transfer route from the 6-methoxyl to the acetyl groups, namely a para-typed push-pull system, is presumed to be formed on the same ring.

The absorption and fluorescence bands of III and IV were shifted to longer wavelength regions by introducing acetyl groups into I and II, as shown in Table 1. This indicated the promotion of an electron-transfer character from the methoxyl substituents to the coumarin ring in both compounds. Compound III had a quantum yield of 0.06 , increased by the acetyl group, while that for IV decreased to less than 0.01 . Hammett's substituent constants ( $\sigma$-values) take different signs according to the positions of substituents in substituted benzenes. For example, the methoxyl group acts as an electrondonating group at the para-position, but as an electronwithdrawing group at the meta-position. The acetyl carbonyl group also has a stronger electron-withdrawing effect than dose the lactone carbonyl group, as reflected by the $\sigma$-values.

The results suggested that the arrangement of the methoxyl group at the 6-position and the acetyl group at the 3-position significantly contributed to the increase in the quantum yield of III through a push-pull system between these groups. On the other hand, the lowered quantum yield of IV was presumed to have been due to the decreased contribution to the push-pull system of the 7-methoxyl group, which corresponds to the metaposition of the 3-acetyl group.

These results indicated that III is superior to IV in sensitivity when they are applied to analytical reagents. Fluorophores such as IV have already been used as good fluorescence derivatization reagents, for example, 7methoxycoumarin-3-carbonyl chloride ${ }^{18}$ or 7-methoxycoumarin-3-carbonyl azide ${ }^{4}$ for alcohols and 3-bromoacetyl-7-methoxycoumarin ${ }^{6}$ for carboxylic acids. Actually, when the derivatizations of lauric acid with 3bromoacetyl-6- (type III) ${ }^{19}$ and 7-methoxycoumarins (type IV) ${ }^{6}$ as an example were attempted for a comparison, it was found that their fluorescence quantum yields for derivatized products in methanol were $0.25^{20}$ for the former and $0.02^{6}$ for the latter, respectively. This result is in accord with predictions based upon the above considerations.

\section{Effect of a methyl group}

A 3-acetyl group was found to appreciably contribute to the fluorescence enhancement of $I$, as shown in the quantum yield of III. The 6-methoxyl group in III corresponded to the meta-position, according to the DSB-model, for the electronic effect of the lactone carbonyl group. In the Hammett rule ${ }^{17}$ for substituted benzenes, a methyl group always acts as an electrondonating group at both the meta- and para-positions, unlike the action of the methoxyl group. Compounds $\mathbf{V}$ and VI were prepared in order to examine the electronic effects of the methyl group on the fluorescence charactaristics of III and IV. Introducing a methyl group to the 7-position of III significantly enhanced the fluorescence from the observed quantum yield, to 0.25 for $V$. The quantum yield of $I V$, compared with that of VI, was also slightly restored by introducing a methyl group.

This effect of the methyl group supports the usefulness of the DSB-model for considering coumarin fluorophores. Furthermore, we estimated from these results that the structural requirements for good coumarin fluorophores in new reagent design are to hold an ether bond, an electron-donating alkyl group and an electronwithdrawing group, such as an acetyl group at the 6,7 and 3 positions, respectively.

\section{Dimethoxycoumarins}

Compound VII afforded a high quantum yield of 0.25 compared with those of the corresponding monomethoxycoumarins, I and II. Although the reason for the increase in the fluorescence of VII remains obscure in considerations based on the electron-transfer effects between the substituents, the greater contribution of the 6-methoxyl group compared with that of the 7-methoxyl group to the fluorescence of VII was estimated based on a comparison of the $\lambda_{\mathrm{UVS}}$ and $\lambda_{\mathrm{FS}}$ of I, II and VII. More remarkable is the quite high quantum yield of 0.52 of 
VIII, as shown in Table 1. This apparently indicates that introducing an acetyl group to the 3-position of VII caused an increase in the quantum yield. Figures 1 and 2 show the absorption and fluorescence spectra of III, IV and VIII for a comparison.

The absorption band of VIII is presumed to be made up of a superposition of bands III and IV. In contrast, an intense band was evident in its fluorescence spectrum. Compound VIII may have another electron-transfer route from 6-methoxyl to acetyl groups, such as a by-pass between the 7-methoxyl and lactone carbonyl groups, and have two push-pull systems through donor and acceptor groups. The substituents in each route are in para-relationships with each other. The mutual effects between two electron-transfer routes seem to contribute to the high quantum yield of VIII.

To elucidate the high quantum yield of VIII, timeresolved fluorescence spectra and the fluorescence lifetimes of III, IV and VIII were measured in methanol. Singly-exponential fluorescence decay with lifetime of $5.34 \mathrm{~ns}$ was observed for VIII, of which the emission seems to comprise of a single component. The fluorescence decays of III and IV were also singlyexponential with lifetimes of 4.44 and $0.3 \mathrm{~ns}$, respectively. Since the lifetime of VIII was comparable to that of III, the main component of the emission of VIII may be of III.

It was suggested that the push-pull system between the 6-methoxyl and 3-acetyl groups, rather than between the 7-methoxyl and lactone carbonyl groups, effectively contributes to the CT-structure of VIII in the excited state to cause intense fluorescence. However, further studies, such as the role of the lactone carbonyl group for the fluorescence of VIII, are necessary to confirm the presence of two push-pull systems. We thus found from these results that the methoxyl substituents at the 6- and 7-positions on coumarin are at least required for strongly emitting fluorophores, and also that an additional substitution of an electron-withdrawing group, such as an acetyl group at the 3-position, is quite effective for fluorescence enhancement. In connection with this finding, IX having methyl groups at the 6- and 7positions, exhibited no fluorescence, which may be due to a weaker electron-donating characteristic of the methyl group compared with that of the methoxyl group.

Such knowledge can be further extended to various coumarin reagents having 6,7-diether bonds and an electron-withdrawing group at the 3-position. This is also supported by the high quantum yields (above 0.8 ) of the coumarin derivatives obtained by the derivatization of fatty acids with 3-bromoacetyl-6,7-methylenedioxycoumarin $^{7}$ or 3-bromoacetyl-6,7-benzocrowned-couma$\operatorname{rin}^{21}$, as reported.

Thus, the construction of push-pull systems between substituents through $\pi$-electron media, such as intramolecular CT, may be a useful approach to the development of new analytical reagents.

The authors wish to thank the staff of the Analytical Center

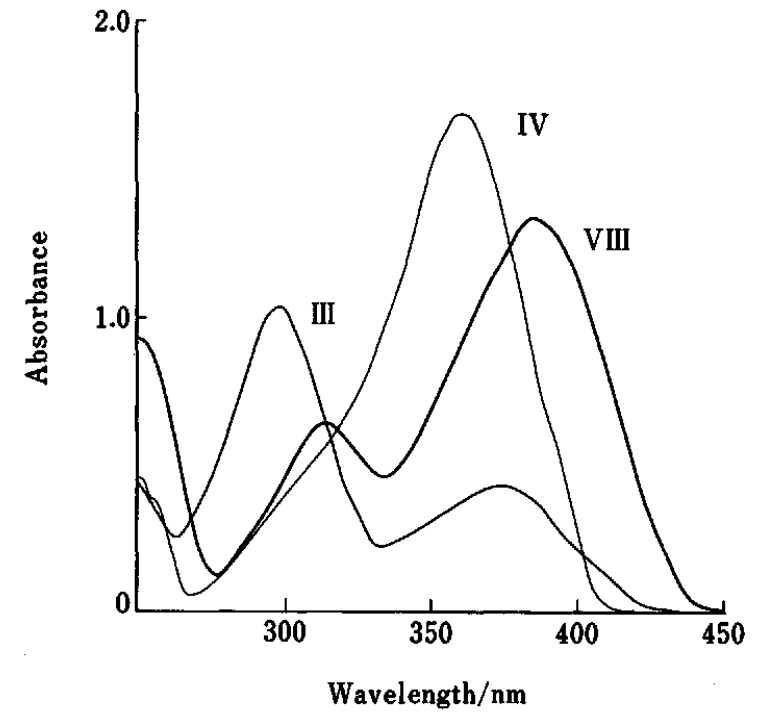

Fig. 1 Absorption spectra of III, IV and VIII in methanol.

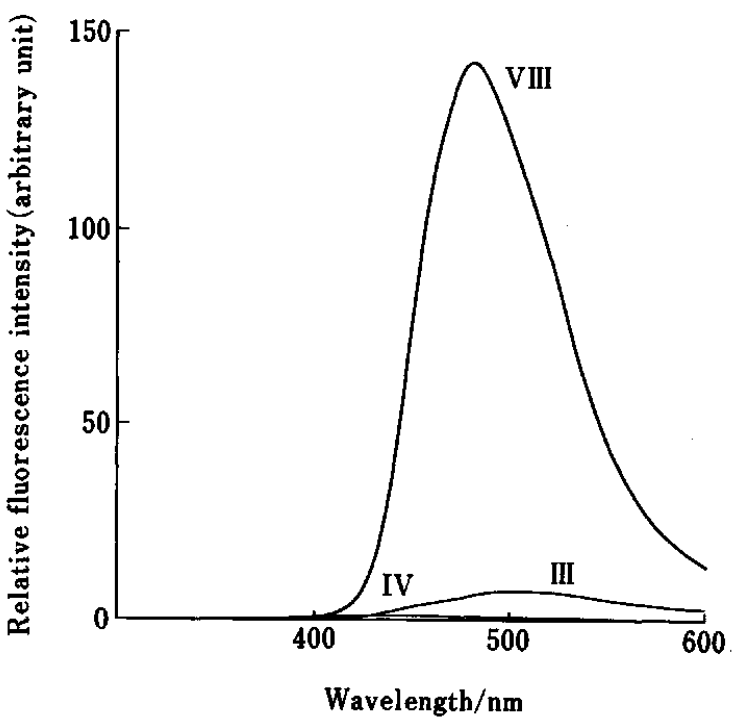

Fig. 2 Fluorescence spectra of III, IV and VIII in methanol.

of Horiba Seisakusho for measurements of the time-resolved fluorescence spectra and fluorescence lifetimes.

\section{References and Notes}

1. T. Hinohara, K. Amano and K. Matsui, Nippon Kagaku Kaishi, 1976, 247.

2. I. Abe, J. Koga and N. Kuroki, Nippon Kagaku Kaishi, 1974, 1744.

3. A. Takadate, T. Tahara, H. Fujino and S. Goya, Chem. Pharm. Bull., 30, 4120 (1982).

4. A. Takadate, M. Irikura, T. Suehiro, H. Fujino and S. 
Goya, Chem. Pharm. Bull., 33, 1164 (1985).

5. A. Takadate, I. Yagashiro, M. Irikura, H. Fujino and S. Goya, Chem. Pharm. Bull., 37, 373 (1989).

6. A. Takadate, T. Masuda, C. Tajima, C. Murata, M. Irikura and S. Goya, Anal. Sci., 8, 663 (1992).

7. A. Takadate, T. Masuda, C. Murata, C. Haratake, A. Isobe, M. Irikura and S. Goya, Anal. Sci., 8, 695 (1992).

8. S. Goya, A. Takadate, H. Fujino, M. Otagiri and K. Uekama, Chem. Pharm. Bull., 30, 1363 (1982); A. Takadate, M. Irikura, Y. Ohkubo, S. Goya and M. Otagiri, ibid., 35, 2104 (1987); M. Irikura, A. Takadate, S. Goya and M. Otagiri, ibid., 39, 724 (1991).

9. T. Masuda, C. Murata, A. Takadate, T. Tanaka, M. Irikura and S. Goya, Abstract of papers, The 55th Symposium on Analytical Chemistry, Toyama, 1994, p. 251.

10. H. Gunther, J. Prestien and P. Joseph-Nathan, Org. Magn. Resonance, 7, 339 (1975).

11. A. H. Jackson and J. A. Martin, J. Chem. Soc. (C), 1966, 2222.

12. R. Adams(ed.), “Organic Reaction”, Vol. VII, John Willey and Sons, Inc., New York, 1953, pp. 1 - 58.

13. E. C. Horning and M. G. Horning, J. Am. Chem. Soc., 69, 968 (1947).

14. R. Baker and J. L. Castro, J. Chem. Soc. Perkin Trans. 1, 1990, 47; R. S. Mali, V. J. Yadav and R. N. Zaware, Indian J. Chem., 21B, 759 (1982); R. A. Glennon, S. M. Liebowitz, D. Leming-Doot and J. A. Rosecrans, J. Med. Chem., 23, 990 (1980); F. S. H. Head and A. Robertson, J.
Chem. Soc., 1930, 2434; W. Baker, J. F. W. McOmie and D. Miles, J. Chem. Soc., 1953, 820.

15. C. A. Parker and W. T. Rees, Analyst [London], 85, 587 (1960).

16. K. Yagi, Z. Yoshida and T. Tabata, "Keikou (Fluorescence, in Japanese)", 4th ed., pp. 27 -42, Nankoudou, Tokyo, 1964.

17. T. H. Lowry and K. S. Richardson, "Mechanism and Theory in Organic Chemistry", 2nd ed., pp. 130-134, Harper \& Row, Publishers, New York, 1981.

18. C. Hamada, M. Iwasaki, S. Goya, K. Zaitsu and Y. Ohkura, The 100th Annual Meeting of Pharmaceutical Society of Japan, Tokyo, April 1980, p. 567; C. Hamada, M. Iwasaki, N. Kuroda and Y. Ohkura, J. Chromatogr. Biomed. Appl., 341, 426 (1985).

19. $\mathrm{Mp} 147-148^{\circ} \mathrm{C}$. NMR $\left(\mathrm{CDCl}_{3}\right) \delta: 3.88\left(3 \mathrm{H}, \mathrm{s}, \mathrm{C}_{6-}\right.$ $\left.\mathrm{OCH}_{3}\right), 4.77\left(2 \mathrm{H}, \mathrm{s}, \mathrm{C}_{3}-\mathrm{COCH}_{2-}\right), 7.07\left(1 \mathrm{H}, \mathrm{s}, \mathrm{C}_{5}-\mathrm{H}\right), 7.28$ $\left(1 \mathrm{H}, \mathrm{d}, \mathrm{C}_{7}-\mathrm{H}\right), 7.34\left(1 \mathrm{H}, \mathrm{d}, \mathrm{C}_{8}-\mathrm{H}\right), 8.59\left(1 \mathrm{H}, \mathrm{s}, \mathrm{C}_{4}-\mathrm{H}\right)$. MS $m / z: 296\left(\mathrm{M}^{+}\right), 298\left(\mathrm{M}^{+}+2\right)$.

20. $\mathrm{Mp} 96-97^{\circ} \mathrm{C}$. NMR $\left(\mathrm{CDCl}_{3}\right) \delta: 0.88(3 \mathrm{H}, \mathrm{t}$, laurate$\left.\mathrm{CH}_{3}\right), 1.26-2.49\left(20 \mathrm{H}, \mathrm{m}\right.$, laurate- $\left.\mathrm{CH}_{2}\right), 3.87\left(3 \mathrm{H}, \mathrm{s}, \mathrm{C}_{6}-\right.$ $\left.\mathrm{OCH}_{3}\right), 5.38\left(2 \mathrm{H}, \mathrm{s}, \mathrm{C}_{3}-\mathrm{COCH}_{2-}\right), 7.05\left(1 \mathrm{H}, \mathrm{s}, \mathrm{C}_{5}-\mathrm{H}\right), 7.27$ $\left(1 \mathrm{H}, \mathrm{s}, \mathrm{C}_{7}-\mathrm{H}\right), 7.33\left(1 \mathrm{H}, \mathrm{s}, \mathrm{C}_{8}-\mathrm{H}\right), 8.59\left(1 \mathrm{H}, \mathrm{s}, \mathrm{C}_{4}-\mathrm{H}\right)$. MS $m / z: 416\left(\mathrm{M}^{+}\right)$.

21. A. Takadate, T. Masuda, C. Murata, T. Tanaka, H. Miyahara and S. Goya, Chem. Lett., 1993, 811.

(Received October 24, 1994) (Accepted December 7, 1994) 